\title{
PERVAPORATION PROCESS USING A THERMAL GRADIENT AS THE DRIVING FORCE*
}

\author{
A C M FRANKEN**, M H V MULDER and C A SMOLDERS \\ University of Twente, Department of Chemical Engineering, $P O$ Box 217, 7500 AE Enschede \\ (The Netherlands)
}

(Received December 28, 1988, accepted in revised form May 7, 1990)

\section{Summary}

A new process design for pervaporation is described in which a composite membrane, consisting of a selective hydrophilic toplayer and a microporous hydrophobic sublayer, is used [1] The feed mixture is brought into contact with the hydrophlic layer At the permeate side of the membrane a permeate-absorbing liquid is brought into contact with the porous sublayer The driving force for this process is caused by the thermal gradient that exists between the warm feed side of the membrane and the cold permeate side The restricting condition of this process design is that the liquid at the downstream side does not penetrate into the pores of the hydrophobic membrane

In this design, the equipment generally needed in conventional pervaporation processes to produce a reduced partial pressure at the permeate side and to condense the permeating vapour is no longer necessary

The performance of the membranes is comparable to those in a conventional pervaporation process

\section{Introduction}

Pervaporation is a membrane process where a liquid is in direct contact with a dense polymer film (feed side) and in which the permeatıng product is removed as a vapour at the other side of this film (permeate side) by applying a reduced partial pressure. In most cases this reduced partial pressure is achieved either by creating a vacuum or by employing a carrier gas.

Pervaporation can be used to separate liquids which are difficult to separate by distillation such as azeotropic mixtures and mixtures with close boiling points. Although some research is being conducted in the field of separations of hydrocarbons [2-5], most of the research is concentrated on aqueous/organic mixtures [5-10]. Especially for the dehydration of organic mixtures pervaporation seems to be a promising technique [5-9]. Within this field the separation of ethanol/water mixtures is the subject on which most of the re-

*Paper presented at IMTEC '88, Sydney, N S W , Australia, November 15-17, 1988

** Present address Centre for Membrane and Separation Technology, University of New South Wales, P O Box 1, Kensington, N S W 2033 (Australıa) 
search has been focused [6-9]. So far, the only commercial application of the pervaporation process is the dehydration of organic solvents, especially of alcohols, using PVA membranes [11,12].

The separation potential of pervaporation for mixtures of organic components and water as well as for non-aqueous organic mixtures is definitely prom1sing in spite of the fact that pervaporation is a relatively complex process compared to other membrane processes such as reverse osmosis. Rautenbach and Albrecht $[3,4]$ state that the specific costs of pervaporation will always be high, because the process requires a heat transfer interface, since the evaporation enthalpy necessary for the phase change of the permeate has to be supplied, and secondly the modules must be designed for a low pressure drop at the permeate side, because the principle of pervaporation is very sensitive to varying permeate pressures.

In this paper a new process design using a thermal gradient as the driving force is described which minimizes the disadvantages described above.

\section{Background}

Although thermally driven membrane processes are known for more than a century, it was less than 10 years ago before one of its representatives, membrane distillation, became of considerable interest. Membrane distillation is a distillation process in which two aqueous liquids with different temperatures are separated by a microporous hydrophobic membrane. In this process the pores of the microporous membrane, which are not wetted by the liquid mixtures at the feed side or the permeate side, act as a vapour phase. The vapour pressure difference $\Delta P_{\mathrm{v}}$, resulting from the temperature difference $\Delta T$ across the membrane, causes vapour molecules to be transported from the warm feed side to the cold permeate side.

The transport mechanism of membrane distillation involves three steps. 1 evaporation at the warm feed side of the membrane;

2. transport of the vapour through the pores of the hydrophobic membrane,

3. condensation of the vapour at the cold permeate side of the membrane.

The separation mechanism of membrane distillation is based on the vapourlıquid equilibrium. If a solution of an inorganic salt in water is used only water vapour will pass through the membrane. On the other hand, the selectıvity of a solution of two (or more) volatile components is determined by the vapourliquid equilibrium. This indicates the limited possibilities of membrane distillation for the treatment of solutions with several volatile components. Membrane distillation is not a real alternative for distillation, because it offers no advantages in difficult separation problems such as azeotropic mixtures. Therefore, the main applications of membrane distillation deal with the production of pure water from aqueous solutions of inorganic material for instance the production of boiler feed water [13] and the desalination of sea water [14]. 
Pervaporation processes are known since the beginning of this century, but similar to membrane distillation, the interest in this separation technıque is of more recent date. The breakthrough for pervaporation came in 1982, when the German company GFT patented a composite membrane for the separation of aqueous mixtures of ethanol and started to commercialize the pervaporation process.

In a pervaporation process, one side of a non-porous membrane is in direct contact with a liquid mixture, whereas the permeated product is removed from the other side of the membrane as a vapour. This is effectuated by keeping the partial vapour pressure at the permeate side below that of the liquid feed mixture. Although many different embodiments of pervaporation exist, most of them have in common that the reduced partial pressure is acheved by creating a vacuum or by employing a carrier gas.

In vacuum operation only a small pressure loss can be allowed at the permeate side, since an increase in partial downstream pressure directly influences flux and selectivity negatively. Therefore, vacuum operation is regarded as critical, since large apparatus volumes are necessary, leakage problems may appear, oxygen might diffuse into the apparatus which would lead to oxidation, etc.

Application of a carrier gas downstream does not involve the problems of a vacuum apparatus. Nevertheless, the use of a carrier gas and a condensor is technically very costly and, moreover, because of the lower temperature level needed in the condensor, even partial recovery of the heat of evaporation needed for pervaporation is usually not possible.

A reduced partial pressure at the permeate side can also be achieved by a temperature difference between feed side and permeate side of the membrane In literature this has been described by Aptel et al. in a membrane operation called "thermo-pervaporatzon" [5]. The thermo-pervaporation apparatus essentially consists of a pervaporation membrane, which separates the hot liquid feed at the upstream side and a downstream compartment with a cold wall. The liquid permeating through the membrane evaporates, diffuses through the downstream compartment and condenses on the cold wall. The condensed permeate is drawn off for storage in a container. The major disadvantage of this mode of operation is the difficulty to maintain the vapour space at the downstream side, resulting inevitably in high module costs.

Very often it is difficult to assign a certain process to one of the three categories described. For instance, the GFT process generates a low partial pressure by using a vacuum pump; then the pump is switched off and the reduced partial pressure is maintained by a condensor situated outside the membrane stack. At regular intervals the pump is switched on to remove inert gases which hinder the diffusion of the permeating components. Although this system is sometimes called thermo-pervaporation, vacuum operation with a discontinuous use of the vacuum pump is a more accurate description. 
The transport mechanism of pervaporation essentially involves the following steps:

1 selective sorption of components of a liquid mixture into the membrane at the feed side;

2 selective diffusion through the membrane;

3. desorption into a vapour phase at the permeate side.

In contrast to membrane distillation, the selectivity of the pervaporation process is not determined by the vapour-liquid equilibrium of the liquid mixture, but by the solute-polymer interactions. The selectivity towards a liquid mixture is determined by selective sorption into the membrane and selective diffusion through the membrane. Thus pervaporation can be used to separate organic liquids which are difficult to separate by distillation.

\section{Description of the thermally driven pervaporation process}

A new process design using a thermal gradient as the driving force has been developed. In this design a composite membrane consisting of a dense permselectıve hydrophilic toplayer and a hydrophobic microporous sublayer is used. The warm liquid feed is brought in direct contact with the permselective toplayer and the cold permeate-absorbing liquid is brought in direct contact with the porous sublayer at the downstream side of the composite membrane (Fig. 1).

The transport mechanusm of this pervaporation process essentially consists of the following five steps:

1. selective sorption of components of a liquid mixture into the toplayer of the membrane at the feed side;

2. selective diffusion through the toplayer of the membrane;

3. desorption into a vapour phase at the interface of the selective toplayer and the microporous sublayer;

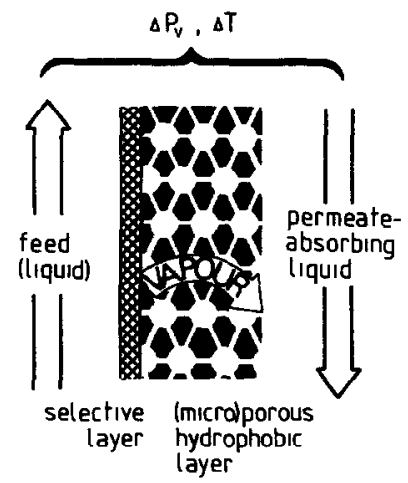

Fig 1 Pervaporation process using a thermal gradient as the driving force 
4. transport of vapour through the pores of the hydrophobic sublayer of the membrane;

5. condensation of vapour at the downstream side of the membrane.

In this process the first three steps are identical to the transport mechanism in a conventional pervaporation process which makes use of vacuum or carrier gas. Furthermore, step 4 and 5 of this mechanism resemble the last two steps of a membrane distillation operation. In fact all water selective membranes that have been developed for pervaporation processes in general can be used as a permselective toplayer in this specific pervaporation process and this specific design is that a hydrophobic porous sublayer is necessary. However, hydrophobicity of sublayer is not the factor which determines the feasibility of this pervaporation process. The only restriction is that the permeate-absorbing liquid at the downstream side of the membrane should not penetrate into the pores of the porous sublayer.

During steady-state operation the permeate-absorbing liquid at the downstream side has the same composition as the permeate. Although it is not necessary that the permeate-absorbing liquid has the same composition as the permeate, it is preferable. Simple calculations show that the selectivity of the process alters in such a way that an equilibrium value of the composition of the permeate-absorbing liquid is pursued.

The driving force for this process is a vapour pressure difference which results from the temperature difference across the membrane. In Fig. 2 the temperature profile and the corresponding vapour pressure profile across the composite membrane are given schematically.

The transport of heat from the bulk of the feed solution to the membrane surface and from the membrane surface to the bulk of the permeate-absorbing liquid are both influenced by among others the temperature level, module parameters and especially by the velocity of the flowing liquid.

The heat needed for the evaporation of the permeate at the interface of the non-porous toplayer and the porous sublayer of the membrane has to be sup-
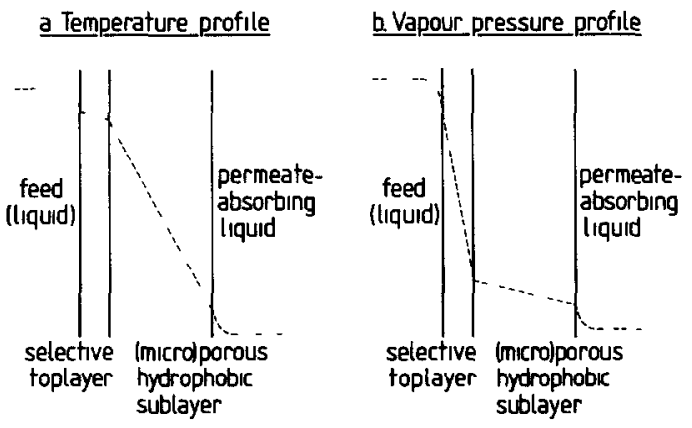

Fig 2 Temperature profile (a) and partıal vapour pressure profile (b) across a membrane 
plied by the liquid feed. In the same way the heat of condensation is directly supplied to the permeate-absorbing liquid. Similar to membrane distillation, both evaporation and condensation of the permeating components worsen the effect of temperature polarization [13].

Heat transfer by conductance through the porous sublayer has a lower value than the heat transfer by conductance through the non-porous toplayer. Because of the high porosity of the sublayer (in case of Accurel membranes the overall porosity is ca. $\mathbf{8 0 \%}$ ), this layer acts as a thermally insulating layer. The effect of the heat transfer by conductance can be illustrated by means of a resistance model as given in Fig. 3.

The heat resistance is given as the membrane thickness divided by the thermal conductivity, $\delta_{\mathrm{m}} / k_{\mathrm{m}}$. The heat resistance of the porous sublayer can be calculated by means of the following formula:

$\frac{\delta_{\mathrm{sub}}}{k_{\mathrm{sub}}}=\frac{\delta_{\mathrm{sub}}}{\left(\epsilon k_{\mathrm{aur}}+(1-\epsilon) k_{\mathrm{PP}}\right)}$

Knowing that $k_{\text {air }}=0.02 \mathrm{~W} / \mathrm{m}-{ }^{\circ} \mathrm{C}$ and $k_{\mathrm{PP}}=0.18 \mathrm{~W} / \mathrm{m}-{ }^{\circ} \mathrm{C}$ it can be calculated that $k_{\text {sub }}$ has a value of about $0.05 \mathrm{~W} / \mathrm{m}-{ }^{\circ} \mathrm{C}$. Comparing this value with the value of the thermal conductivity of the swollen toplayer $\left(k_{\text {top }}=040-0.45\right.$ $\mathrm{W} / \mathrm{m}-{ }^{\circ} \mathrm{C}$ ) and considering that the sublayer is much thicker than the toplayer, it is evident that the heat resistance of the porous sublayer is much higher. For example, if the thickness of the porous sublayer is $100 \mu \mathrm{m}$ and the thickness of the toplayer is $10 \mu \mathrm{m}$, it can be calculated that the heat resistance of the porous sublayer is about 80 times the heat resistance of the swollen toplayer. Because no accumulation of heat occurs, the heat flux through the toplayer is equal to the heat flux through the sublayer. Therefore, the temperature difference across the sublayer is about 80 times higher than the temperature difference across the toplayer.

This phenomenon is very favourable for the separation mechanism of the membrane operation under study In Fig. $2 b$ the partial vapour pressures of the components across the membrane are given. These partial vapour pressures are given by the temperatures of the feed solution and the permeate-

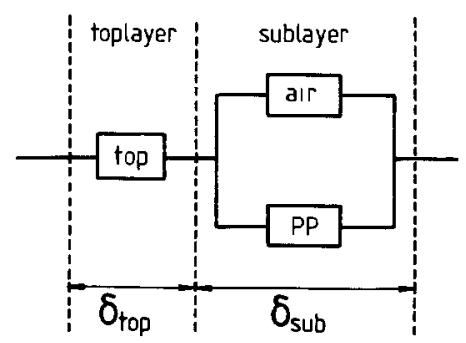

Fig 3 Heat resistance model 
absorbing liquid respectively. Because the transport of the vapour through the porous sublayer is much faster than the transport of the liquid through the non-porous toplayer, it can be concluded that the vapour leaving the non-porous toplayer is immediately drawn away and transported through the pores of the sublayer. This results in a rather flat vapour pressure profile across the porous sublayer, whereas the profile across the toplayer is very steep.

Comparing the temperature profile and the vapour pressure profile it can be concluded that condensation of permeate will not take place inside the pores of the sublayer, because the vapour pressure at any point in the porous sublayer is lower than the maximum vapour pressure given by the local temperature. Furthermore, the flux and selectivity are determined by the vapour pressure difference across the toplayer of the membrane. If this vapour pressure difference increases, then both flux and selectivity will increase.

The major advantage of this thermally driven pervaporation process over conventional pervaporation processes is that the membrane process as a whole can be simplified because of the substantially simpler process design. Therefore, the equipment costs will be lower. Furthermore, specific advantages of this thermally driven pervaporation process are that the transfer of latent heat of vaporization to the evaporation surface (the membrane) is an integrated part of the process, partial recovery of the heat of condensation is possible when the process is conducted in counter-current flow and the process is no longer sensitive to downstream pressure losses.

A disadvantage of this new mode of pervaporation compared to conventional pervaporation systems is that the permeate-absorbing liquid should not penetrate into the pores of the porous sublayer. This means that the permeateabsorbing liquid must have a surface tension which is higher than a critical surface tension for penetration [15]. In practice, this means that only aqueous solutions or solutions of DMSO can be used as a permeate-absorbing liquid if polypropylene membranes are used. Furthermore, fluxes are generally lower as compared to vacuum pervaporation due to the relative high partial pressure on the downstream side of the membrane.

A typical field of application for thermally driven pervaporation is dehydration of organic liquids with a low water content. To prevent wetting of the porous membrane layer by the permeate, the dense toplayer must have a high intrinsic selectivity towards water. Dehydration of mixtures of ethanol/water or acetic acid/water are the best known examples of mixtures that can be separated by this process.

\section{Experimental}

In our investigations, both flat and capillary hydrophobic microporous polypropylene membranes (Accurel, obtained from Enka AG) with an average pore size of $0.2 \mu \mathrm{m}$ were used as sublayer. The flat membranes have a thickness 
of about $160 \mu \mathrm{m}$ and the capillary membranes (type $\mathrm{R} 5 / 1$, inner diameter of $1.2 \mathrm{~mm}$ ) have a thickness of about $300 \mu \mathrm{m}$.

Three polymers have been used for the dense toplayer: cellulose acetate (Eastman CA 398-3-5), polysulfone (Union Carbide P 3500) and poly (vinyl alcohol) (Aldrich, $\mathrm{MW}=126,000$, degree of saponification: 98\%). CA and PSf were dissolved in a suitable solvent of analytical grade. Using method 3 for the production of the composite membrane (see below), CA was dissolved in DMSO (dımethylsulphoxide). PVA was dissolved in ultrafiltered water.

In our investigations the following four methods to deposit a selective layer onto a microporous membrane have been used:

1. casting of a polymer solution onto a glass plate and subsequent evaporation of the solvent;

2. casting of a polymer solution onto a glass plate and subsequent coagulation in a non-solvent bath;

3. castıng of a polymer solution onto the microporous sublayer directly;

4. dipcoating ("evaporation-deposition" method [16]).

In the first and second method the remaining homogeneous film is sandwiched with the microporous Accurel membrane to form a bi-layer membrane, which is clamped into the pervaporation cell.

In the third and fourth method a polymer is dissolved in a solvent, which does not wet the microporous sublayer. In our investigations DMSO and water were used as solvents. In the "evaporation-deposition" method, the polymer solution is brought into contact with one side of the microporous membrane and a low partial pressure (vacuum or carrier gas) is applied at the other side. In this way evaporation of the solvent through the pores of the polymer takes place. After a certain time the redundant polymer solution is removed, leaving a deposited polymer film on the microporous sublayer.

The composite membranes were tested using both a conventıonal pervaporation cell (Fig. 4) and a cell suitable for thermally driven pervaporation (Fig. 5).

In the experiments with flat membranes, the bottom disk of the permeation

a pervaporation apparatus

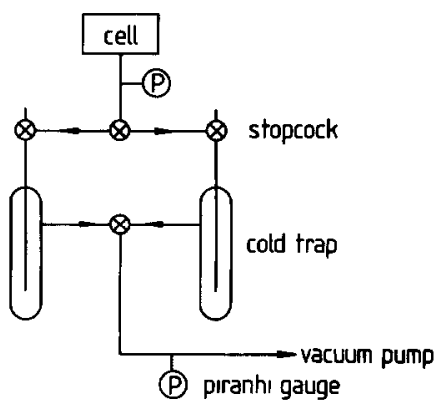

bepermeation cell

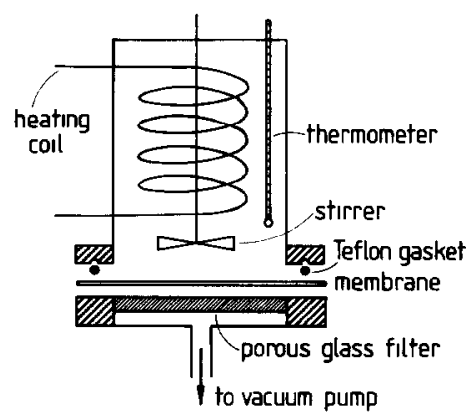

Fig 4 Conventional pervaporation apparatus (a) pervaporation apparatus, (b) permeation cell 
cell is fitted with porous glass $(0.1 \mathrm{~m}$ in diameter) to support the membrane. A teflon gasket is placed on the membrane before the upper part of the cell is matched. The whole unit is tightened by means of a sovirel clamp. A heating coll is placed into the upper compartment to adjust a preselected temperature and to keep the temperature of the liquid feed constant. A mechanical stirrer was used to minimize the effects of temperature and concentration polarization. A thermometer is placed in the cell to determine the temperature of the liquid feed.

Capillary membranes were fixed into a glass module with a length of $0.25 \mathrm{~m}$ and coated on the inside with a dilute PVA solution in water by means of the "evaporation-deposition" method. After drying, the module was given a heat treatment $\left(30 \mathrm{~min}\right.$ at $\left.130^{\circ} \mathrm{C}\right)$.

The permeation cell or the module is connected to two cold traps in parallel. This makes it possible to take samples at any time without interrupting the permeation run. Vacuum at the downstream side is maintaned at a pressure less than $100 \mathrm{~Pa}$ by a Crompton Parkinson vacuum pump. The pressure is measured by an Edwards Pirani gauge.

Permeation experiments were carmed out for eight hours. After about three hours steady state conditions were reached. A product sample is taken at least every hour.

The apparatus that is used for the thermally driven pervaporation exper1ments is given in Fig. 5. In this mode of operation the feed mixture is kept at a constant temperature in the reservoir that is placed in thermostat 1 . The total volume of the feed side is about three litres. Iwakı MD 6-Z magnet pumps

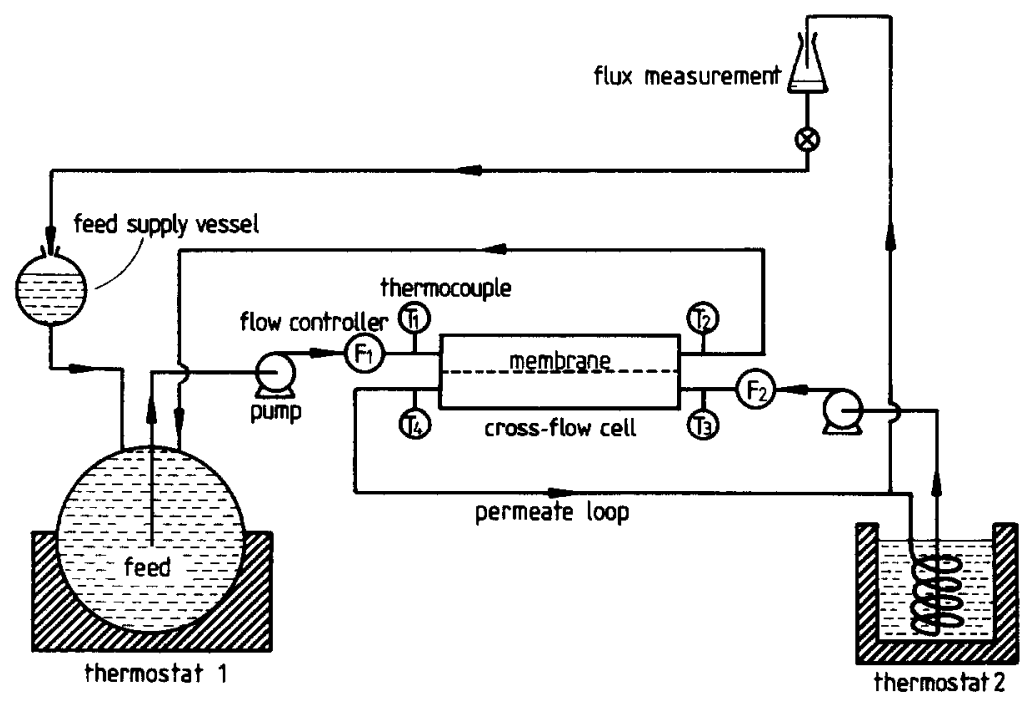

Fig 5 Thermally driven pervaporation apparatus. 
are used to pump the liquids along the membrane at feed and permeate side with a constant crossflow velocity. Temperatures are measured by means of thermocouples. The feed mixture is pumped back to the reservoir and recirculated again. The depletion of the feed as a result of the flux through the membrane is supplied by the feed supply vessel.

At the permeate side a cooling coil is used instead of a reservoir, thus leading to a total volume at the permeate side of about $300 \mathrm{ml}$. The flux is measured by means of an overflow measurement. During the period that no flux is measured the overflow point is connected to the feed supply vessel. In this way the depleted ethanol/water mixture is recirculated.

In the experiments, in which flat membranes were used, a crossflow cell is used, the dimensions of the cell at both feed and permeate side being $200 \times 50 \times 5$ $\mathrm{mm}$ (length $\times$ width $\times$ depth). The membrane is placed in the cell in such a way that the selective layer of the membrane is in contact with the feed. In this cell the membrane is supported at both sides by a wire-netting with meshes of about $5 \mathrm{~mm}$. Because this process is conducted without any pressure difference, this construction provides a sufficient support. The crossflow velocity at both sides of the membrane is approximately $0.2 \mathrm{~m} / \mathrm{sec}$.

In the experiments with capillary membranes the modules were used d1rectly. The feed is pumped through the bore of the capillaries with a crossflow velocity of about $04 \mathrm{~m} / \mathrm{sec}$; at the shell side a crossflow velocity of about 0.2 $\mathrm{m} / \mathrm{sec}$ is maintained.

In both cases the feed mixture and the permeate mixture are pumped in counter-current flow through the pervaporation cell.

\section{Results and discussion}

Although pervaporation experiments with a thermal gradient as a driving force provide a good alternative for dehydration of an alcohol rich feed side, they are not a "laboratory-friendly" method of pervaporation, because the experıments are very time-consuming. In our experiments, the experimental conditions were chosen in such a way that the feed concentration hardly changed during the experiment and that the permeate concentration was measured as a function of time of operation. Once again it must be stated clearly that in this mode of pervaporation the concentrated feed is the desired product and that our laboratory conditions do not resemble the industrial type of application. If the experiments were performed with a changing feed concentration, the assessment of flux and selectivity would have been nearly impossible within a reasonable time scale.

With a constant feed concentration and assuming a constant composition of the permeating vapour, the downstream side of the membrane can be considered as a continuous stirred tank reactor [17]. Consequently, the concen- 
tration at the downstream side reaches a steady-state value according to the following exponential function,

$$
C_{\mathrm{t}}=C^{*}\left(1-\exp ^{-(J A t / \rho V)}\right)
$$

The total permeation yield (expressed by $J A t / \rho$ ) must be about five times the permeate volume $V$ to reach the steady-state value $C^{*}$ within $1 \%$. As the permeate volume is about $300 \mathrm{ml}$, the total permeation yield should be about 1500 $\mathrm{ml}$. With a flux of $J$ of about $0.1 \mathrm{~g} / \mathrm{m}^{2}$-sec and a membrane area $A$ of $80 \times 10^{-4}$ $\mathrm{m}^{2}$, it takes about $500 \mathrm{hr}$ to reach a steady state value! Therefore, only a few experiments were carried out with the pervaporatıon process using the thermal gradients as the driving force. The results are given in Table 1.

The first experiment was performed with a sandwich-membrane prepared by the first method. In this case only one temperature difference has been ınvestigated. The flux was $0.033 \mathrm{~g} / \mathrm{m}^{2}-\mathrm{sec}$ and the selectıvity 2.4 . If these results are compared with a conventional pervaporation experiment of the same membrane $\left(J=0.095 \mathrm{~g} / \mathrm{m}^{2}\right.$-sec and $\left.\alpha=60\right)$, the thermally driven pervaporation process seems rather unattractive. However, it must be realized that the conventional pervaporation is carried out at a low pressure at the permeate side $(<100 \mathrm{~Pa})$ and that the thermally driven pervaporation process was carried out at a low temperature and at a low temperature difference. In largescale applications of the conventional pervaporation process the downstream vacuum will be higher (thus giving a lower flux and selectivity) and the feed

\section{TABLE 1}

Pervaporation experiments using a thermal gradient

\begin{tabular}{|c|c|c|c|c|c|c|c|c|c|c|c|}
\hline $\begin{array}{l}\text { Exp } \\
n r\end{array}$ & $\begin{array}{l}\text { Prepara- } \\
\text { tion } \\
\text { method }\end{array}$ & $\begin{array}{l}\text { Polymer/ } \\
\text { solvent }\end{array}$ & $\begin{array}{l}\text { Ethanol } \\
\text { in feed } \\
\text { (wt \%) }\end{array}$ & $\begin{array}{l}R e \\
\text { feed }\end{array}$ & $\begin{array}{l}R e \\
\text { perm }\end{array}$ & $\begin{array}{l}\text { Temp } \\
\text { feed } \\
\left({ }^{\circ} \mathrm{C}\right)\end{array}$ & $\begin{array}{l}\text { Temp } \\
\text { perm } \\
\left({ }^{\circ} \mathrm{C}\right)\end{array}$ & $\begin{array}{l}\Delta T \\
\left({ }^{\circ} \mathrm{C}\right)\end{array}$ & $\begin{array}{l}\text { Flux } J \\
\left(\mathrm{~g} / \mathrm{m}^{2}-\mathrm{sec}\right)\end{array}$ & $\begin{array}{l}\text { Select1- } \\
\text { vity } \\
\alpha\end{array}$ & $\begin{array}{l}\text { Thickness } \\
\text { selective } \\
\text { layer } \\
{[\mu \mathrm{m}]}\end{array}$ \\
\hline 1 & 1 & $\mathrm{CA} /$ acetone & 35 & 680 & 880 & 270 & 190 & 80 & 0033 & 24 & 30 \\
\hline 2 & 2 & $\begin{array}{l}\text { PSf/DMAc } \\
\text { coagulated in } \\
\text { 1sopropanol }\end{array}$ & 35 & 930 & 1580 & 375 & 210 & 165 & 0004 & 100 & \\
\hline 3 & 3 & CA/DMSO & 35 & 730 & 930 & 292 & 208 & 84 & 0055 & 24 & 10 \\
\hline 4 & & & 35 & 1000 & 1160 & 387 & 233 & 154 & 011 & 35 & \\
\hline 5 & & & 35 & 1200 & 1370 & 478 & 252 & 226 & 017 & 48 & \\
\hline 6 & & & 35 & 1250 & 1530 & 486 & 404 & 82 & 0105 & 22 & \\
\hline 7 & 3 & CA/DMSO & 35 & 730 & 930 & 293 & 235 & 58 & 010 & 19 & 5 \\
\hline 8 & & & & 930 & 1140 & 375 & 261 & 114 & 019 & 28 & \\
\hline 9 & & & & 700 & 1440 & 462 & 294 & 168 & 030 & 40 & \\
\hline 10 & 4 & PVA/water & 82 & 560 & 1030 & 670 & 225 & 445 & 0095 & 65 & \\
\hline 11 & & & 80 & 570 & 1600 & 670 & 435 & 235 & 0070 & 55 & \\
\hline 12 & 4 & PVA/water & 82 & 560 & 1160 & 665 & 225 & 440 & 0050 & 105 & \\
\hline 13 & & & 81 & 570 & 1720 & 680 & 425 & 255 & 0042 & 90 & \\
\hline
\end{tabular}


temperature and temperature difference of the thermally driven pervaporation process will be higher (resulting in a higher flux and selectivity).

In experiment 2 it is demonstrated that besides homogeneous films as the selective layer also asymmetric films can be used. In this experiment as asymmetric polysulfone membrane is sandwiched with a microporous Accurel membrane. A separation factor of 10 is achieved with a flux of $0.004 \mathrm{~g} / \mathrm{m}^{2}$-sec.

The effect of the temperature and the temperature difference can be seen if experiments 3-6 are compared. If the temperature difference increases both flux and selectivity increase (see experiments 3-5). Comparing experiments 3 and 6 it is shown that in the latter case the flux is higher because of the higher temperature, whereas the selectivity is about the same. Because the vapour pressure at the permeate side is higher, the driving force across the selective layer is lower. This is analogous to conventional pervaporation experiments where both flux and selectivity decrease when the partial vapour pressure at the permeate side of the membrane is increased [18].

Comparing experiments 3-6 with experiments 7-9, it can be seen that the flux through the membrane is increased by a factor 2 when the thickness of the selective layer is reduced by the same factor. It appears that in both cases the selectivity is mainly influenced by the temperature difference. These observations are an indication that the main resistance for transport through the membrane is formed by the selective layer which is in agreement with the transport mechanism proposed earlier.

Some results obtained with the "evaporation-deposition" method are listed in Table 1 (experiments 10-13). The phenomena, that were observed for the CA membranes, can also be seen for the PVA membranes.

From these results it can be concluded that the best results are obtained with a high feed temperature and a large temperature difference across the membrane. The temperatures for the thermally driven pervaporation process should be in the range of $70-100^{\circ} \mathrm{C}$ for the feed side and in the range of $20-50^{\circ} \mathrm{C}$ for the permeate side in order to achieve an optimal process performance.

Comparison of the results of the thermally driven pervaporation with the results of the conventional pervaporation, listed in Table 2 , shows that both flux and selectivity of the latter mode of operation are higher for the CA membranes. This difference can be explained by the fact that the partial vapour pressure at the permeate side in the conventional mode of operation is as low as $100 \mathrm{~Pa}$, whereas the vapour pressure in the thermally driven pervaporation is determined by the temperature of the permeate. For instance, a solution of $20 \mathrm{wt} . \%$ ethanol in water at $20^{\circ} \mathrm{C}$ has a vapour pressure of about $4000 \mathrm{~Pa}$; at $30^{\circ} \mathrm{C}$ the vapour pressure is about $7500 \mathrm{~Pa}$. The flux and selectivity of a conventional pervaporation process decreases also when the partial vapour pressure at the permeate side is raised $[4,18]$. For PVA membranes it is observed that the flux in the thermally driven pervaporation operation is lower than the 
TABLE 2

Conventional pervaporation results (downstream pressure $<100 \mathrm{~Pa}$ )

\begin{tabular}{lllllllll}
\hline $\begin{array}{l}\text { Exp } \\
\mathrm{nr}\end{array}$ & $\begin{array}{l}\text { Prepara- } \\
\text { tion } \\
\text { method }\end{array}$ & $\begin{array}{l}\text { Polymer/ } \\
\text { solvent }\end{array}$ & $\begin{array}{l}\text { Ethanol } \\
\text { in feed } \\
\text { (wt \%) }\end{array}$ & $\begin{array}{l}\text { Re } \\
\text { feed }\end{array}$ & $\begin{array}{l}\text { Temp } \\
\text { feed } \\
\left({ }^{\circ} \mathrm{C}\right)\end{array}$ & $\begin{array}{l}\text { Flux } J(\mathrm{~g} / \\
\mathrm{m}^{2} \text {-sec) }\end{array}$ & $\begin{array}{l}\text { Select1- } \\
\text { vity } \\
\alpha\end{array}$ & Remarks \\
\hline 14 & 1 & CA/acetone & 35 & 500 & 230 & 0095 & 60 & (see exp 1) \\
15 & 1 & CA/DMSO & 35 & 500 & 230 & 022 & 70 & $\delta=8 \mu \mathrm{m}$ \\
16 & 4 & PVA/water & 79 & 440 & 500 & 0105 & 45 & (same \\
17 & & 79 & 490 & 590 & 018 & 35 & membrane as \\
18 & & & 79 & 580 & 680 & 027 & 30 & exp 10/11) \\
19 & 4 & PVA/water & 81 & 430 & 490 & 004 & 55 & (same \\
20 & & 81 & 480 & 590 & 0065 & 47 & membrane as \\
21 & & 80 & 570 & 670 & 009 & 40 & exp 12/13) \\
\hline
\end{tabular}

flux in the conventional type. The selectivity, however, is higher. These latter results cannot be explained directly from the separation mechanism.

Because the partial vapour pressure at the permeate side in a commercial Installation will be in the range of $10^{3}-10^{4} \mathrm{~Pa}$, the differences in flux and selectivity between conventional and thermally driven pervaporation will become smaller.

In our investigations the crossflow velocity was chosen in such a way that the effect of temperature polarization is kept as low as possible. The effect of the crossflow velocity on the flux and the selectivity was measured in membrane distillation experiments [19]. From these experiments it appeared that an effect of temperature polarization occurred, which was more severe if the crossflow velocity was lower. A lower crossflow velocity results in a lower Reynolds number, thus hindering the heat transfer from the bulk of the solution to and from the membrane surface. As a result the temperature at the membrane surface will be lower at the feed side and higher at the permeate side, thus reducing the driving force for pervaporation.

The crossflow velocity also determines the axial temperature drop (respectively rise) in the module. In our investigations the temperature difference between the inlet and outlet feed (respectively permeate-absorbing liquid) always was lower than $1^{\circ} \mathrm{C}$. The temperatures that are given in the tables are mean temperatures. Although the effect of the temperature drop (respectively rise) is not investigated in this study, its effect is very important for the commercial application of thermally driven pervaporation. Only if a distinct difference occurs between inlet and outlet temperature, recovery of most of the heat of condensation and heat losses due to conductance is possible when the process is conducted in counter-courrent flow [13].

A phenomenon which should be avoided in membrane distllation is wetting of the microporous hydrophobic membrane [15]. If only some of the pores of 
the membrane are wetted during membrane distillation, a leak occurs which immediately spoils the permeate quality, especially if a high product quality is desired (e.g. ultra pure water).

Wetting of a few pores by the permeate-absorbing liquid does not affect the process in case of thermally driven pervaporation. In fact, the only effect is a volume reduction of the vapour "compartment" Only if severe wetting of the microporous sublayer occurs (e.g. more than $50 \%$ of the pores in the microporous sublayer being wetted), an effect on the flux and selectivity might be measured.

Nevertheless, care should be taken that a maximum allowable concentration of the organic component in the permeate-absorbing liquid is not exceeded. For ethanol/water mixtures the maximum allowable concentration at the permeate side for Accurel membranes is approximately $40 \mathrm{wt} . \%$ ethanol [15].

\section{Conclusions}

Thermally driven pervaporation provides a simple and effective mode of pervaporation, which is especially suitable for the dehydration of aqueous/ organic mixtures. Furthermore, the selective layer must have a high selectivity towards water in order to avoid wetting of the porous sublayer by the permeateabsorbing liquid. The membranes that were used in our investigation do not yet fit the requirements of a commercial application of thermally driven pervaporation and were merely used to demonstrate the possibilities of the process. The performance of the membranes is comparable to those in a conventional pervaporation process.

\section{Acknowledgement}

This paper is based upon work financially supported by the Mınıstry of Economical Affairs in The Netherlands and Enka A.G. (Product Group Membrana), Wuppertal (Federal Republic of Germany). Enka also supplied the Accurel membranes.

\section{References}

1 A C M Franken, M H V Mulder and C A Smolders, Pervaporation process, European Patent EP 218,019 (German Patent DE 3,536,007)

2 I Cabasso, J Jagur-Grodzinskı and D Vofsi, A study of permeation of organic solvents through polymeric membranes based on polymenc alloys of polyphosphonates and acetyl cellulose II Separation of benzene, cyclohexene and cyclohexane, J of Appl Polym Sc1, 18 (1974) 2137-2147

3 R Rautenbach and $R$ Albrecht, The separation potential of pervaporation Part 1 Discussion of transport equations and companson with reverse osmosts, J Membrane Sc1, 25 (1985) $1-23$

4 R Rautenbach and R Albrecht, The separation potential of pervaporation Part 2 Process desıgn and economıcs, J Membrane Scı , 25 (1985) 25-54 
5 P Aptel, N Challard, J Cuny and J Néel, Application of the pervaporation process to separate azeotropıc mixtures, J Membrane Sc1 , 1 (1976) 271-287

$6 \mathrm{M} \mathrm{H} \mathrm{V}$ Mulder, Pervaporation, separation of ethanol-water and isomeric xylenes, $\mathrm{Ph} \mathrm{D}$ thesis, University of 'Twente, 1984

7 R Y M Huang, Y Xu, Y Jın and C Lıpskı, Novel blended nylon membranes for the pervaporation separation of acetic acid-water and ethanol-water liquid mixture systems, Proceedings of Second International Conference on Pervaporation Processes in the Chemical Industry, San Antonio (U S A ), March 8-11, 1987, Bakısh Materials Corporation, Englewood, NJ, p 225-239

8 I Cabasso and Z -Z Liu, The permselectivity of ion-exchange membranes for non-electrolyte liquid mixtures I Separation of alcohol/water mixtures with Nafion hollow fibers, J Membrane Sc1 , 24 (1985) 101-119

9 A Niemoller, H Scholz, B Gotz and G Ellinghorst, Radiation grafted membranes for pervaporation of ethanol/water-mixtures, J Membrane Sc1 , 36 (1988) 385-404

10 I Blume and R Baker, Separation and concentration of organic solvents from water using pervaporation, Proceedings of Second International Conference on Pervaporation Processes in the Chemical Industry, San Antonı (U S A ), March 8-11, 1987, Bakısh Materials Corporation, Englewood, NJ, p 111-125

11 H Bruschke, Mehrschichtige Membran und ihre Verwendung zur Trennung von Flussigkertsgemıschen nach dem Pervaporationsverfahren, German Patent DE 3220570

12 H E A Bruschke and G F Tusel, Economics of industrial pervaporation processes, in E Drolı and M Nakagakı (Eds), Membranes and Membrane Processes (Proceedings of the Europe-Japan Congress on Membranes and Membrane Processes, Stresa (Italy), June 1822, 1984), Plenum Press, New York, NY, 1986, pp 581-586

13 K Schne1der and T J van Gassel, Membrandestillation, Chem Ing Tech, 56 (1984) 514521

14 A -S Jonsson, R Wimmerstedt and A -C Harrysson, Membrane distillation - A theoretical study of evaporation through microporous membranes, Desalination, 56 (1985) 237-249

15 A C M Franken, J A M Nolten, M H V Mulder, D Bargeman and C A Smolders, Wetting criteria for the applicability of membrane distlllation, J Membrane Sc1 , 33 (1987) 315-328

16 A C M Franken, M H V Mulder and C A Smolders, Verfahren zum Herstellen emer Zwe1schichtmembran, German Patent DE 3707054

17 O Levenspiel, Chemical Reaction Engineerıng, John Wiley and Sons, New York, NY, 1965

18 Q T Nguyen, The influence of operating parameters on the performance of pervaporation processes, AIChE Symp Ser nr 248, Industrial Membrane Processes, Vol 82 (1986) 1-11

19 A C M Franken, J A M Nolten, M H V Mulder and C A Smolders, Ethanol-water separation by membrane distillation Effect of temperature polarization, in B Sedlacek and J Kahovec (Eds), Synthetic Polymeric Membranes (Proceedings of the 29th MicrosymposIum on Macromolecules, Prague, July 7-10, 1986 Walter de Gruyter, Berlın-New York, 1987, pp 531-540 